\title{
A European Model for Public Transport Authorities in Small and Medium Urban Areas
}

\author{
Steve Wright \\ University of Aberdeen
}

\begin{abstract}
Public Transport Authorities (PTAs) are well-established in large urban areas. These dedicated authorities act in the public interest to ensure that a well-functioning, integrated transport system operates within their territory. Within Europe, economic pressures and changes in regulation to encourage more competition are providing the catalyst for municipalities/authorities of all sizes to review the structure under which transport is managed and provided in their jurisdictions and to consider the suitability of establishing a PTA. Based on findings from case studies in eight small and medium urban areas across seven European countries, it is clear that although user needs remain at the center of the actions of a PTA, the level of functionality provided by metropolitan PTAs would not be suitable or possible for a PTA in a small- or medium-size urban area. This paper presents a summary model of the functions/responsibilities and guidelines on the organizational structure that are most suitable for PTAs in small and medium urban areas in Europe.
\end{abstract}

\section{Introduction}

Recent legislation in Europe (European Union 2007) is encouraging a more open and competitive market in public transport provision across territories of all sizes (van de Velde 2008). At the same time, there is the growth in demand for more environmentally-friendly transport initiatives (European Commission 2013), with which local authority transport departments historically have little experience. Coupled with a continuing trend for decentralization of various powers from central governments to the local level (see, for example, Zegras et al. 2013), more areas, including smaller cities and surrounding rural areas, are considering restructuring of transport planning and delivery into operating units and controlling bodies or Public Transport Authorities (PTAs) (see, for example, Schuchmann and Papadimitriou 2009).

PTAs are now well-established in large urban areas, and a pan-European organization, European Metropolitan Transport Authorities (EMTA) (http://www.emta.com/), exists to support and transfer best practices among metropolitan transport authorities. EMTA 
has 27 member cities in which all but one (Vilnius) has a metropolitan area population for which the PTA has responsibility for $1+$ million inhabitants. There is no equivalent organization for smaller cities or regions containing fewer than 1 million inhabitants that are considering establishing a PTA. Therefore, this population figure was used to provide a loose definition to distinguish between large urban areas ( $>1$ million) and small/medium urban areas ( $<1$ million).

This paper draws on all the activities within the EPTA (European Model for Public Transport Authority) Project, a European Territorial Cooperation project that was active between January 2012 and July 2014. The overall objective of EPTA was the transfer of experience, knowledge, and good practices about PTAs, with particular focus on small and medium urban areas. The paper summarizes the capitalization of the project experiences, resulting in a strategic model and a practical guide with concrete suggestions for effective establishment and management of a PTA in small/medium urban areas.

In describing a model and guidelines for PTAs (also referred to as organizing authorities), it is relevant to first consider the International Association of Public Transport (UITP) definition of what PTAs are or should aim to be: "Organising Authorities are organisations which act in the public interest to ensure a well-functioning, attractive, and integrated transport system. They provide the framework for successful public transport directed at economic, social, and environmental value for citizens and business" (UITP 2009).

As illustrated in Figure 1, a PTA makes the link between political decision-makers and public transport operators, as follows:

- PTAs provide the framework to organize and coordinate different mobility options across a defined geographical area to ensure delivery of efficient, comfortable, and high-quality public transport.

- Whether an operator is public or private, the PTA's role is to act within the public interest to ensure that different modes are well-integrated, affordable, and accessible and to organize this in a manner that complies with strategic level goals and targets set by politicians.

- These strategic-level goals can relate to public transport and accessibility targets but also can be related to policies in related fields such as environment, land use, social inclusion, parking, or traffic planning.

- The transport authority has a set and often limited budget with which to achieve this. 
FIGURE 1.

Levels of responsibility in transport provision
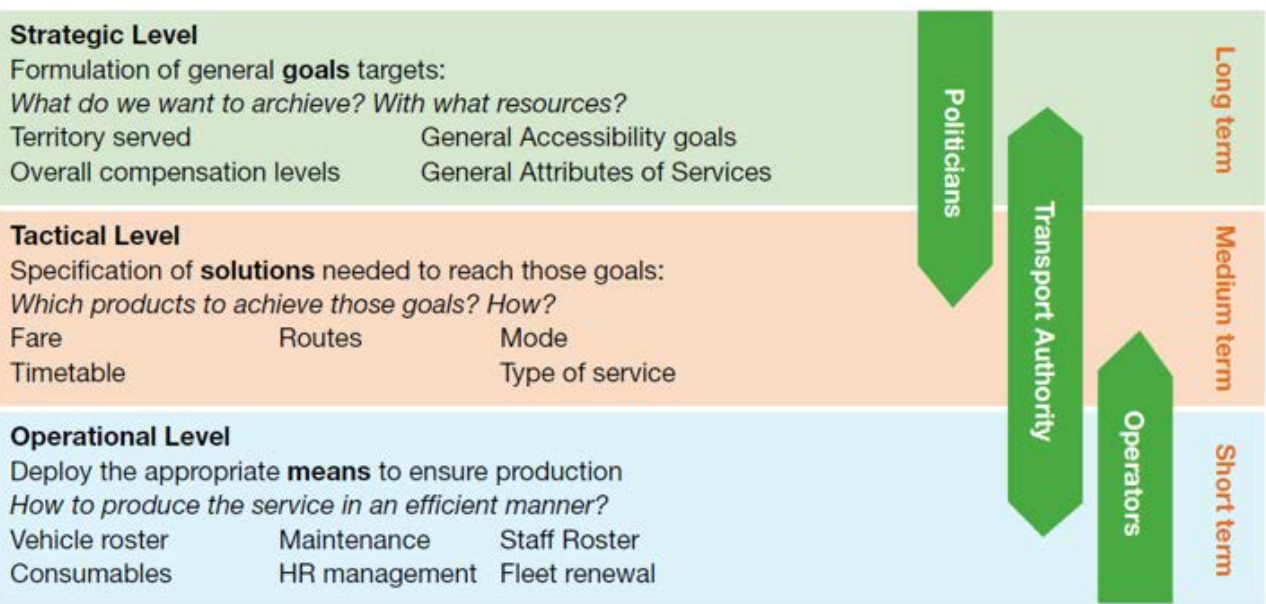

Source: UITP 2005

In practice, it is government officers (at either national, regional, or local level) who ensure compliance with strategic goals. The extent to which a PTA should be involved with strategic- and/or operational-level activities varies according to local circumstance but is largely influenced by the scale of the city/area being served. The next section provides guidance on this.

\section{PTA Model in Large Urban Areas}

It is now universally recognized that large urban/metropolitan areas benefit from having a PTA and, typically, these follow a decentralized organizational structure that is operated by a dedicated statutory agency (CFIT 2001; Atkins 2007; Masa 2009). Previous studies by EMTA (2003), Finn and Nelson (2004), UITP (2011), and Naniopoulos et al. (2012) have identified the main activities and responsibilities in providing transport services for the public. These have been consolidated within EPTA to form seven main pillars, as shown in Table 1. 
TABLE 1. Seven Main Functions of a PTA

\begin{tabular}{|c|c|}
\hline 1. Regulation & $\begin{array}{l}\text { A legal framework gives structure to a PTA to allow it to function in close cooperation with the local government and } \\
\text { operators and to carry out the policies made by policy-makers. A legal framework usually defines the options that are open } \\
\text { to PTAs to implement. In some cases, it may require some additional legislation to be created to allow the PTA to introduce } \\
\text { changes consistent with the regulatory framework for all modes. The framework of activities among stakeholders is strongly } \\
\text { linked to the legal framework governing the PTA. For example, a framework that foresees the presence of structured PTAs } \\
\text { gives them strength and authority to allow the organization to meet its objectives. }\end{array}$ \\
\hline 2. Planning & $\begin{array}{l}\text { The planning function is usually divided into the following categories; Planning Services, Budgeting Resources, and } \\
\text { Operatively Designing/Scheduling Services. These activities themselves could be part of the PTA. On a political and } \\
\text { administrative level, planning should be linked to and influenced by other public planning activities, such as environment, } \\
\text { economics, social, urban, rural, etc. For example, a PTA can be responsible for planning the entire process, including sourcing } \\
\text { resources, budgeting services, and designing/scheduling services, as defined by legal bodies. On the other hand, a PTA can act } \\
\text { as an advisory body, providing assistance to stakeholders, such as local bodies, operators, etc. }\end{array}$ \\
\hline $\begin{array}{l}\text { 3. Tendering / } \\
\text { Awarding }\end{array}$ & $\begin{array}{l}\text { The tendering/awarding procedure usually is regulated by law. It is a crucial function in which the operator(s) are chosen and } \\
\text { a service contract is awarded. A successful PTA can establish criteria and grounds for fruitful cooperation with operators, } \\
\text { based on quality, efficacy, and efficiency. For example, a direct award to an operator does not usually lead to contract } \\
\text { optimization. This may be due to local circumstances-lack of competition, etc. A structured tendering process involving all } \\
\text { stakeholders can lead to improved services designed to meet the needs of users in the most cost-effective manner. }\end{array}$ \\
\hline 4. Integration & $\begin{array}{l}\text { In planning and awarding services, integration and coordination among different modes and stakeholders (other } \\
\text { departments/sectors, such as Health, Education, etc.) that deal with sustainable mobility as a whole represent a strategic } \\
\text { objective for delivering inter-modality and co-modality. Of course, the result (efficient integration) can be a benefit for } \\
\text { the users and also for the contract, distributed between the PTA and the operator(s). For example, service integration can } \\
\text { improve levels in satisfaction for all users, including those who are rural or urban; older adults and persons with disabilities; } \\
\text { commuters; education, health, and social service agencies; leisure establishments; and businesses. Integration between modes } \\
\text { can lead to the development of multimodal networks that include bus, train, metro, tram, car-sharing, bike-sharing, taxis/car } \\
\text { hire with drivers, and parking management. }\end{array}$ \\
\hline 5. Promotion & $\begin{array}{l}\text { The promotion of any service is key to its success. Efficient public transport can shift passengers from individual to collective } \\
\text { modes and from unsustainable to more efficient and economic modes of transport. Promotion of services can be dealt with } \\
\text { at the political or operational levels, particularly within net-cost contracts. For example, a PTA that has awarded a gross-cost } \\
\text { contract has to invest in promotion of services. A PTA has also to invest in promotion if local bodies are deeply interested in its } \\
\text { efficacy. A PTA can ignore promotion and include this function in the responsibility of the operator(s) or other organization(s) } \\
\text { as part of the tendering process. }\end{array}$ \\
\hline 6. Management & $\begin{array}{l}\text { Management of services is usually the responsibility of operators (except for PTAs that operate their own services). A } \\
\text { transport service contract should contain full understanding of the issues from the PTA, including a good knowledge of } \\
\text { the operational activities and meeting the needs of stakeholders. For example, sometimes PTAs manage services themselves, } \\
\text { being owned by local bodies. This usually means that a service contract does not exist. In other cases, it can just own the } \\
\text { buses/trains or even maintain them. }\end{array}$ \\
\hline 7. Control & $\begin{array}{l}\text { Often, the control activity is underestimated. It is important to create trust between the PTA and the stakeholders to } \\
\text { ensure that the design and operation of appropriate services meet the needs of users. Clearly-defined standards and } \\
\text { operational guidelines are required to allow monitoring of performance so good service can be rewarded and poor service } \\
\text { penalized. For example, the real know-how comes from operating and/or from control. Where a contract is foreseen, an } \\
\text { appropriate control structure should be introduced to protect the PTA and users. }\end{array}$ \\
\hline
\end{tabular}

The EPTA Project expanded these seven pillars to identify a larger number of associated key functions or sub-tasks, as shown in Figure 2, in which the inner ring shows the EPTA pillars surrounded by a second ring showing the key sub-tasks or functions in which PTAs can be active. Some of these sub-tasks span more than one pillar. The subtasks shown in Figure 2 combine the tasks and responsibilities of all three actors represented in Figure 1, namely, politicians, transport authorities, and operators. 
FIGURE 2.

Model for a PTA with

full functionality

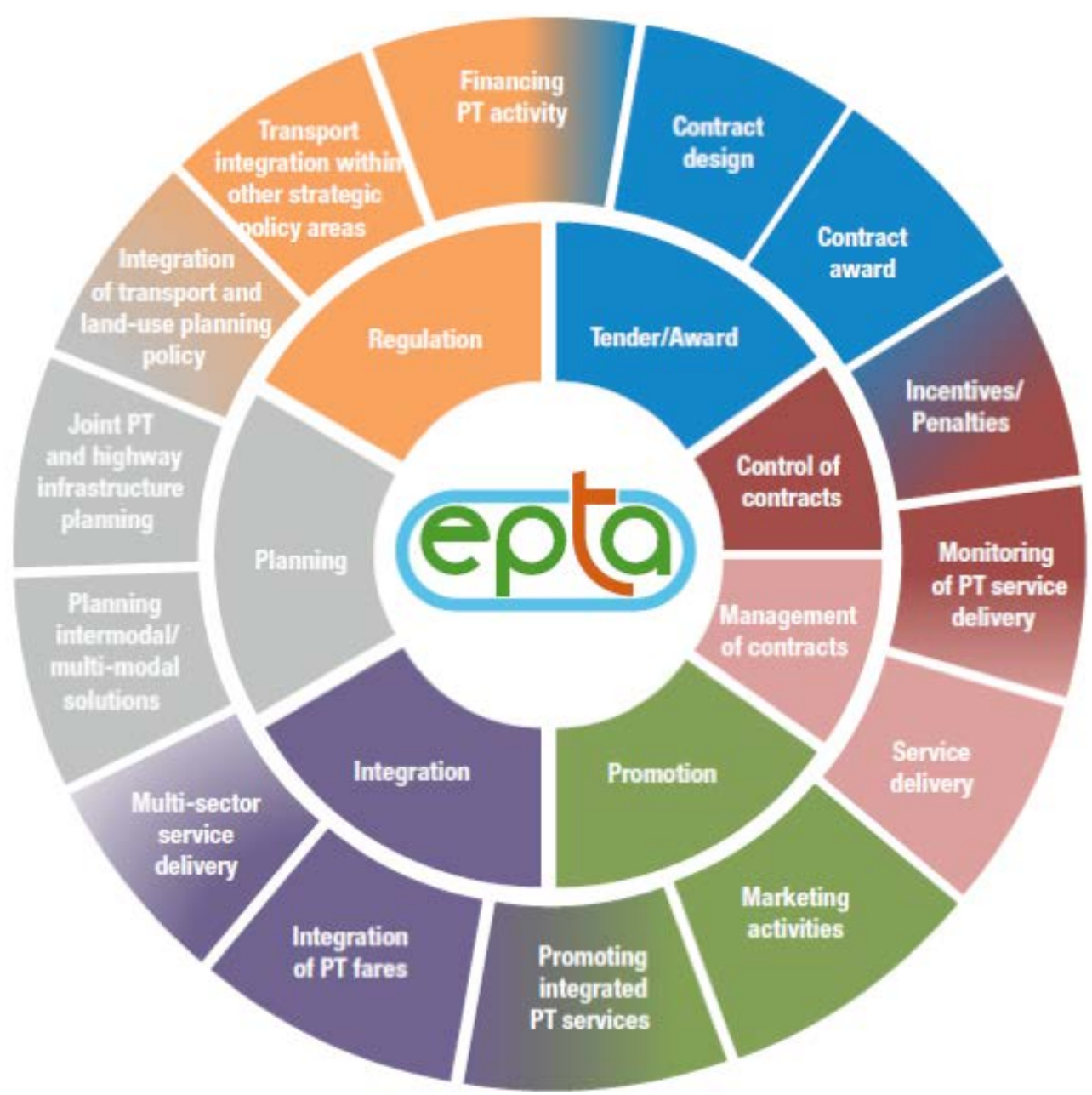

Due to the scale of transport provision required in large metropolitan areas, the PTAs in large cities tend to have an active role in all of the sub-tasks identified in the outer ring of Figure 2. The extent of their involvement varies by sub-task and by local circumstances. Metropolitan PTAs are the main responsible body for all tasks associated with tender/ award, management of contracts, promotion, and integration pillars. The one exception is service delivery, which is largely the domain of the operators; however, even here, PTAs sometimes act as the operator of certain services (Nash and Bray 2014). An EMTA position paper (EMTA 2003), Preston (2010), and, more recently, findings of the CAPRICE project (2011) stress the importance of a strong integration of transport networks and coordination with policies of land planning and urban development. These sub-tasks, associated with the planning and regulation pillars in Figure 2, increasingly are becoming part of the PTA role in large metropolitan cities.

\section{Example for a Large Metropolitan PTA: London}

Transport for London (TfL), the PTA for the Greater London area, has involvement in all the subtasks identified in Figure 2. Its role is to implement the Mayor of London's Transport Strategy (MTS) and manage services across London, for which the Mayor has ultimate responsibility. 
TfL delivers in-house the London Underground (LU), the Docklands Light Railway (DLR), the London Overground, and the London Tramlink. It does not deliver London's bus services, but does manage them. There is a competitive tender process for 700 bus service routes in which the terms of service are prescribed in detail (constructive planning), including service routes, frequencies, and fares. Contracts are awarded on a gross-cost basis, which requires significant staff resources for performance monitoring and revenue enforcement through ticket inspectors.

TfL developed a ticketless "contactless" smart card (Oyster card) for payment on any TfL-managed public transport service. Each week, around 57 million journeys are made using Oyster cards, which are used for more than $85 \%$ of bus passenger journeys.

TfL also acts as the highway and traffic authority for Greater London, with the following responsibilities:

- Full operational responsibility for the Transport for London Road Network (TLRN), which includes $580 \mathrm{~km}$ of major roads, which make up $5 \%$ of London's roads but carry more than $30 \%$ of its traffic.

- Strategic responsibility for coordinating works and ensuring the free flow of traffic (including pedestrians) on the wider Strategic Road Network (SRN), an additional $500 \mathrm{~km}$ of Borough-maintained A roads.

- Management and maintenance of all of London's 6,000 traffic signals and real-time operational control of the road network through the London Streets Traffic Control Centre (LSTCC).

- Management and operation of the Congestion Charging, Low Emission Zone (LEZ), and Source London schemes, as well as enforcement of decriminalized traffic offenses on the TLRN, including parking, loading, and bus lane regulations.

Operational revenues, including fares and congestion-charge income, account for more than $47 \%$ of total funding and amount to approximately E5billion p.a. The remainder of the revenue comes in the form of a central government grant, but this is increasingly being replaced by local taxation (in the form of local business rates and taxes) over which TfL has more control.

The MTS is the principal policy tool through which the Mayor and TfL exercise their responsibilities for the planning, management, and development of transport in London. The development of this strategy has been delegated to TfL although the Mayor retains responsibility for approving consultation documents. TfL was delegated responsibility for undertaking the necessary consultation exercises and impact assessments.

The above illustrates the extent of the tasks for which a large metropolitan PTA has responsibility. However, this level of activity requires significant resources in terms of finance and staffing. TfL employs more than 20,000 staff and annually requires more than E5billion in funds in addition to the operating revenues generated. 


\section{PTA Model in Small/Medium Urban Areas}

Although the model described in the previous section (and illustrated in Figure 2) may represent the typical situation for a PTA in a very large metropolitan city, the EPTA Project determined that such a level of functionality would not be suitable or possible for a PTA in a small or medium urban area ( $<1$ million inhabitants). PTAs in some large metropolitan areas have powers devolved to them by legislation, enabling them to set policy specific to their jurisdiction with statutory powers of enforcement and autonomy to raise their own financing to fund services and PTA activities, but smaller cities and surrounding rural areas do not have such powers. The result of this is that there is simply not the expertise and influence at the policy level or the financial resources and manpower at the operational level in a small/medium urban area PTA to take an active role in all the sub-tasks identified in Figure 2.

The development of a PTA model for small/medium urban areas was shaped during the course of the EPTA Project through the transfer of experiences among project partners and local experts at a series of eight workshops and nine training courses and staff exchanges. In addition, several of the PTA model sub-tasks illustrated in Figure 2 have been investigated in more detail within eight feasibility studies by project partners to assess the relevance and importance of these sub-tasks in different operating environments and under differing governance structures. These eight feasibility study sites include:

- Thepta (Greece): "Tendering and Awarding the Bus Transport Services in the City of Thessaloniki"

- Alot (Italy): "Business Plan for a PTA—Awarding the Service"

- SRM Bologna (Italy): "Design and Control of a Public-Transportation Service Contract"

- Brasov (Romania): "Structure and Role of the Brasov Metropolitan PTA"

- Almada (Portugal): "Mobility House of Almada"

- Rogaland (Norway): "Integration and Simplification of the Fare and Ticketing System in Rogaland"

- Razlog (Bulgaria): "Bicycle Sharing System and Car Pooling System"

- Prague Suchdol (Czech Rep): “Establishing More and Better Consultation with Local Partners and the Public"

Analysis of these feasibility studies revealed that, despite the studies having very different aims and environments in which they were examined, a number of key findings emerged:

1. The level of involvement by the PTA needs to be based on the scale of the operation. PTA involvement has a resource and time cost associated with it. What works in big cities often is not appropriate or possible in small towns and medium-size cities. In general, the larger the population covered, the more functions the PTA can take responsibility for.

2. Contract design and award are key to PTAs of any size. This is the area in which PTAs have the power to influence who operates the services and the way in which 
operators act, which has a bearing on quality and levels of service, expectations for supply of service performance data, and levels of integration with other operators and other modes. It dictates the operator requirements for service monitoring and for supporting integration action that the PTA may implement. The type of contract can influence the marketing strategy and approach of an operator-e.g., net cost contracts place the onus on the operator to attract passengers, which tends to result in operators providing innovative and well-marketed services. (For more detailed information and advice on implementation, see the EPTA online training module on Contract Design and Award at http://www.eptaproject.eu/training/on-line-training/ on-line-training-tool-contractaward/.)

3. Large metropolitan PTAs are inclined to have a hands-on approach to service monitoring and promotion activities rather than delegating these tasks to operators. Medium and small cities, on the other hand, do not have the resources to dedicate significant manpower to service promotions and monitoring of services and, instead, tend to focus on approval and supervision of operator-led monitoring of services and on activities related to integration among operators, modes, and sectors. (For more detailed information and advice on implementation, see the EPTA online training module on Monitoring and Incentives at http://www.eptaproject.eu/training/ on-line-training/monitoring/.)

4. Large metropolitan cities take an active role in policy forming to ensure that policies in land planning and urban development are integrated with transport. They also are integral to the planning of transport infrastructure investments that impact on their area (e.g., airport, rail, and road-building initiatives). Medium- and small-city PTAs have little or no input into these matters, as their planning is undertaken at a higher level (often national or regional government) and is paid for through national or local government funding. It is vital that there is better communication and integration between the PTA and these external departments at the planning stage. The EPTA Project identified the need for a more formalized mechanism by which local needs and concerns can be more strongly represented in the policy and planning process. This is relevant not only to medium- and small-city PTAs having a voice in regional or national policy and planning, but also for single municipalities within a large metropolitan city being able to feed into higher-level policy making and planning that impacts their citizens. The recommendation from EPTA is that a policy- and strategic-level planning committee be constituted that provides the platform for coordination and cooperation between local municipalities, PTAs, and metropolitan/ regional government. The committee should include PTA representatives, national/ regional government decision-makers/politicians, locally-elected politicians, and local government officers, as well as specialist groups of experts (e.g., university, third sector, etc.) to advise and feed into the planning and decision process to help ensure that local interests are being represented without political bias.

5. The policy- and strategic-level planning committee (as detailed above) could also preside over financing and fundraising/spending decisions. This makes it more plausible to adopt local funding strategies such as local levies on fuel sales and employment or local sales taxes. These provide a democratic and locally-accountable 
means of raising funding for public transport. The presence of locally-elected representatives on the committee will ensure that local citizen preferences are upheld and could result in a more flexible and locally-focused funding stream that enables PTAs to better respond to the needs of their people rather than being restricted by national or regional funding constraints. (For more detailed information and advice on implementation, see the EPTA online training module on Funding at http://www. eptaproject.eu/training/on-line-training/funding/.)

Based on the above findings and recommendations from the EPTA Project, Figure 3 illustrates the PTA model for a small rural to medium urban area.

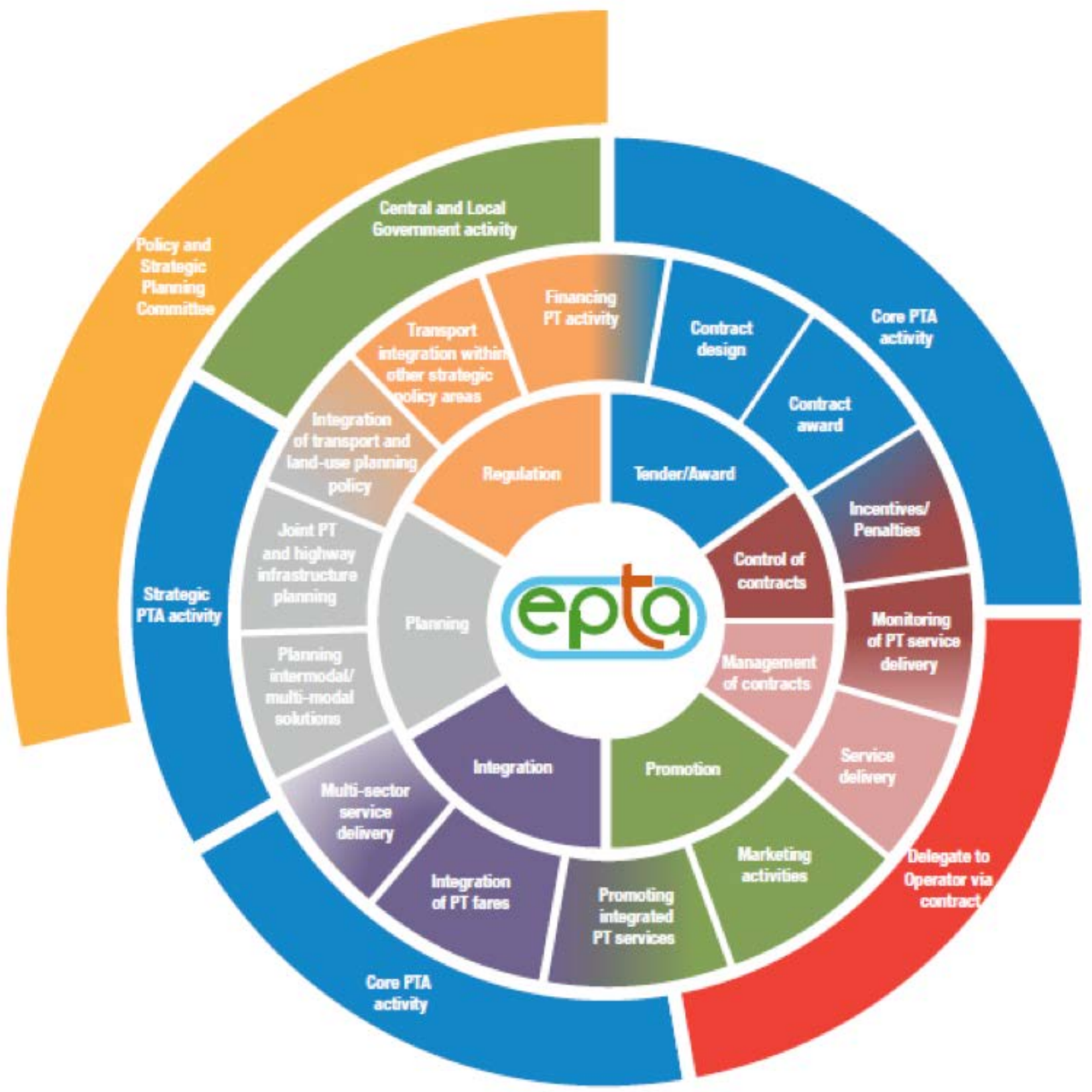

FIGURE 3. Model for PTA in medium or small city 


\section{PTA Structure in Small/Medium Urban Areas}

The findings from the EPTA Project suggest that the most cost-effective PTA structure for small and medium cities appears to be that of a decentralized agency that is contracted/ commissioned by the regional or national government. The primary focus, then, is to provide approval and supervision of services and to facilitate/enforce integration among operators, modes, and sectors.

If the model of Figure 3 is adopted, including the formation of a policy and strategic planning committee, then the PTA can operate as an independent organization with the following advantages:

- Local financing and funding become possible.

- User needs remain at the center of the actions of the PTA.

- The focus on a more limited set of functions allows more expertise in these functions to be developed by employees, ensuring effective control of performance of the contract of transportation services to high-quality standards.

- Many of the risks of providing services and resources required for service data collection and promoting services are borne by the operators.

- Labor-related issues associated with in-house service provision are displaced to the contracted operator, which often has more flexibility in dealing with/avoiding such issues.

The biggest advantage of the above approach is that the cost of PTA provision can be relatively modest since the staffing levels are much lower than those required for a largecity PTA, in which involvement in service design, monitoring, and promotion is generally much greater. The agency approach also allows for flexibility in staffing when required, as it is easier to appoint additional staff on a temporary or short-term basis than if a relatively small municipality were to appoint staff directly. The establishment of a policy and strategic planning committee also removes the need for the PTA to have a top-heavy management structure of locally-elected politicians, since they sit on the committee alongside the PTA representatives rather than on a PTA board of directors.

All the above contributes to a very lightweight staffing structure while remaining responsive to peaks in activity/workloads. This results in a low-cost solution to forming a PTA, which is a critical requirement in small and medium cities.

Examples of PTA structure and functions/responsibilities are provided below for three EPTA project partners: SRM Bologna, the proposed Brasov Metropolitan Area PTA, and the proposed PTA for the Razlog region.

\section{Example for a Medium City PTA: Bologna, Italy}

SRM (Reti e Mobilità Srl) is the agency that acts as the PTA for the Province of Bologna, serving a population of almost 1 million across 60 municipalities. It is a joint-stock company whose capital is entirely publicly-owned by the Municipality and Province of Bologna and was established in 2003 when several functions of public interest were delegated to it from local governmental bodies in the field of public transport. 
The budget to fund the public transport services delivered totals 96M Euros per annum, with more than $80 \%$ of this provided by the Regional Government (Emilia-Romagna Region in the case of SRM) based on parameters such as total public transport km per year, etc. The remaining funding comes from local bodies. SRM manage the budget and controls the main assets necessary to provide public transport services. With this budget, it has complete control of the tender and award process and funds the local operators on the basis of a contract for service. Management and control of contracts also are tasks delegated to SRM. SRM has some role in promotion of service integration, but strategic functions such as planning and setting fare levels are retained by local municipalities and the Province of Bologna; policy/regulation is mainly set by the Regional government. As a result, SRM has a very light staffing structure, employing only nine persons. The budget for this is provided from a $0.5 \%$ cut of the Regional PT Funding (360,000 Euro per year) plus around 400,000 Euro per year from rent relating to transport infrastructure.

In the recent months, SRM has tendered for and been awarded the management of on-street parking on behalf of the Municipality of Bologna. As a result, an additional two staff will be appointed. This illustrates the flexibility and ability to respond to additional opportunities offered by the agency approach to PTA delivery in small and medium cities.

\section{Proposal for a Medium City PTA: Brasov, Romania}

The Brasov Metropolitan Area PTA was established as a reaction to the highly-unregulated manner in which transport services are provided in the Brasov City Region (approximately 450,000 inhabitants in a relatively compact area). The PTA was developed during the EPTA Project and has gained from European best practices identified both within and outside the EPTA partnership.

The PTA for the Brasov Metropolitan Area is basically an NGO agency of local public bodies. This structure is in line with the Romanian legislative framework and, for the first time, allows small communities and local authorities to be involved in organizing the public transport system in and around their local community. A newly-formed Association for the Sustainable Development of Public Transport Brasov was established in 2013 and includes the 15 communities in the metropolitan area together with the Brasov Metropolitan Agency PTA. This association will make strategic decisions on policy/regulation and planning. The initial approach is for the Brasov PTA to tackle a limited set of functions such as tendering/awarding and control with inputs to planning and regulation through the Association for the Sustainable Development of Public Transport Brasov; other functions will be integrated into the PTA model as the organization grows and a favorable local critical mass is in place.

The permanent staffing structure for the PTA will be small (4-8 full-time employees); specialists can be hired temporarily for specific tasks when necessary. Given the reduced staff structure, a large part of the responsibility for monitoring of the service contracts will be transferred to selected operators. The PTA will establish procedures for monitoring and will verify compliance and collect monitoring process data. To compensate for the small PTA staff, it will be desirable, where possible, to use ICT technology, especially for service-monitoring purposes. 
The annual budget for the proposed PTA is around 157,000 Euro, but a minimal budget would allow functioning of the PTA with only 100,000 Euro/year.

\section{Proposal for a PTA in a Small Town and Surrounding Region: Razlog, Bulgaria}

The Municipality of Razlog, located in southwest Bulgaria, includes a small population $(21,709)$ with centers in the towns of Razlog $(12,852)$ and Banska $(3,000)$. The region is a mountain tourism destination characterized by the rapid growth of ski resorts on the fringes of the towns and large fluctuations in seasonal employment. A rail link and intercity coach services pass through the region, but the only current form of local public transport operating within the municipality is a limited bus service. The low and variable demand for transport makes all but the most socially-essential bus routes unaffordable.

Regulation, strategic planning, and funding for transport are controlled at the national government level. Currently, the Municipality is responsible for procurement of the essential local bus lines. It also coordinates the routes regarding the needs of the different public transport users, and special routes and timetables are prepared for student transportation. It is clear that the Municipality can continue to provide this minimum level of transport service without the need to establish a PTA; however, seasonal demands for transport are not being adequately met. Although tourists can afford to use taxis, there is a need to accommodate more transport demands of the local population. Furthermore, to support business growth, especially in the tourism sector, additional transport options are required for lower-paid workers to access the main employment sites.

A culture of informal carpooling exists in the region and, due to the flat geography and relatively short distances between the main settlements and employment centers, there is potential for greater amounts of cycling. As a result, a PTA will be established to plan, implement, and manage a shared public bicycle system and coordinate a formalized carpooling service, including promotion measures for both. Although this could be established as a section within the municipality, increasing the staffing capacity to provide these services cannot be justified due to the seasonal nature of the demand. Therefore, it was considered more advantageous to establish a specialized NGO to act as a PTA agency to handle the operation of the system in cooperation with the Municipality of Razlog. The PTA will not require funds from the Municipal budget and will seek to develop funding partnerships with local businesses and through formation of public/private partnerships for construction of elements of the bike-share system. Given the local circumstances and limited staff resources, it was felt that the PTA agency would be better able to mobilize the support of all stakeholders to build and maintain a wide, active transport and carpooling system. Once the active travel measures become established, there is the possibility for the procurement and management of public transport services to migrate to PTA agency control.

The need for and roles of a PTA in an environment such as Razlog Municipality are different from that of a medium-to-large city. The greater focus on "soft" transport measures is moving out of the traditional focus of PTAs (providing public transport services) into the wider domain of providing alternatives to private car use. 


\section{Conclusions}

This paper provides strategic guidance on the structure and functions of a PTA for small to medium urban areas. This provides a useful tool for policy decision-makers and stakeholders to follow when considering setting up and/or managing a PTA in their territory. The key guidelines are summarized below.

\section{Guidelines for PTA Functions}

User needs remain at the center of the actions of a PTA, but the level of functionality provided by metropolitan PTAs would not be suitable or possible for a PTA in a small or medium urban area. Figure 3 presented the model for a PTA in small and medium urban areas, and the main elements of this model are the following:

- Contract design and award are key to PTAs of any size.

- Thereafter, the primary focus of a PTA is to provide approval and supervision of services and to facilitate/enforce integration among operators, modes, and sectors.

- The PTA delegates to operators the resource-intensive daily activities (service delivery, monitoring, and promotion).

- The focus on a more limited set of functions (in comparison to Metropolitan PTAs) allows more expertise in these functions to be developed by PTA staff, ensuring effective control of performance of the contract for transportation services to high-quality standards.

- Many of the risks of providing services and resources required for service data collection and promoting services are borne by the operators. Labor-related issues also are displaced to the contracted supplier.

- Integration should remain a core element of PTA activity in small and medium cities.

- Local needs and concerns should be more strongly represented in the policy and planning process through formation of a policy and strategic planning committee, enabling formal inputs from the PTA and local stakeholders to planning and regulation/policy decisions.

\section{Guidelines for PTA Structure}

The most cost-effective PTA structure for small/medium cities appears to be that of a decentralized agency that is contracted/commissioned by the regional or national government. The PTA can operate as an independent organization with the following advantages:

- Local financing and funding become possible.

- The cost of PTA provision can be relatively modest since the staffing levels are much lower than those required for a large-city PTA in which involvement in service design, monitoring, and promotion is generally much greater.

- The agency approach also allows for flexibility in staffing when required, as it is easier to appoint additional staff on a temporary or short-term basis than if a relatively small municipality were to appoint staff directly. 
- Formation of a policy and strategic planning committee removes the need for the PTA to have a top-heavy management structure; locally-elected politicians can sit on the committee rather than on the PTA board of directors.

The result is a very lightweight staffing structure that remains responsive to peaks in activity/workloads, which provides a low-cost solution to forming a PTA and is essential in small/medium cities.

The focus of this paper is firmly based on European experience, but it is likely that the general principles of the model being proposed have relevance to small/medium urban areas outside Europe. In the United States, public transit agencies typically provide similar functions to those identified in Figure 2; in some cases, they are part of city government and in others they are independent public agencies. Typically, they provide the majority of their primary services in-house and do not contract them out (Booz Allen Hamilton 2011). However, U.S.-focused research (Iseki 2008) points towards the increasing efficiency of smaller transit agencies as their level of contracting increases. Therefore, it is likely that the European model proposed for small/medium cities (based on contracting operations and monitoring) illustrated in Figure 3 will also have relevance in the U.S.

\section{Acknowledgments}

This work was sponsored by the EPTA Project under the European Commission's Interregional Cooperation Programme INTERREG IVC, financed by the European Union's Regional Development Fund.

\section{References}

Atkins. 2007. "Review of Reform Options for Metropolitan Transport Governance. Final Report to Passenger Transport Executive Group." January. http://www.pteg.net/ system/files/general-docs/pteg_Atkins_Governance_report_200702.pdf, accessed January 2015.

Booz Allen Hamilton, in association with P. N. Bay. 2011. "Regional Organizational Models for Public Transportation." Prepared under TCRP Project J-11/Task 10. Transportation Research Board, Washington, DC. http://www.apta.com/resources/reportsandpublications/Documents/Organizational_Models_TCRP_J11_Task10.pdf, accessed May 5, 2015.

CAPRICE Project. 2011. "CAPRICE Project Good Practice Guide: A Decision Maker's Guide." http://www.caprice-project.info/IMG/pdf/Guide_Caprice_2Mo.pdf, accessed January 7, 2015.

CfIT. 2001. "Study of European Best Practice in the Delivery of Integrated Transport." Commission for Integrated Transport. November.

http://webarchive.nationalarchives.gov.uk/20110303161656/http://cfit.independent. gov.uk/pubs/2001/ebp/index.htm, accessed January 7, 2015. 
EMTA. 2003. "Position of the Association of European Metropolitan Transport Authorities, 50th Anniversary of the European Conference of Ministers of Transport, Brussels." April. http://www.emta.com/IMG/pdf/emta_position_50_years_cemt_en.pdf, accessed January 7, 2015.

European Commission. 2013. "Together Towards Competitive and Resource-Efficient Urban Mobility." Communication from the Commission to the European Parliament, the Council, the European Economic and Social Committee, and the Committee of the Regions. European Commission, Brussells. December. http://ec.europa.eu/transport/themes/urban/doc/ump/com(2013)913_en.pdf, accessed January 7, 2015.

European Union. 2007. "Regulation (EC) No 1370/2007 of the European Parliament and of the Council. October 23, 2007, Public Passenger Transport Services by Rail and by Road and Repealing Council Regulations (EEC) Nos. 1191/69 and 1107/70. L315/1-13, Brussels." Official Journal of the European Union. http://eur-lex.europa.eu/LexUriServ/ LexUriServ.do?uri=OJ:L:2007:315:0001:0013:EN:pdf, accessed January 7, 2015.

Finn, B., and Nelson, J. D. 2005. "A Functional Model for an Urban Passenger Transport Authority. Competition and Ownership in Land Passenger Transport." Selected Papers from the 8th International Conference (Thredbo 8), Rio De Janeiro, September 2003: 559-575.

Iseki, H. 2008. "Economies of Scale in Bus Transit Service in the USA: How Does Cost Efficiency Vary by Agency Size and Level of Contracting?" Transportation Research Part A, 42: 1086-1097.

Naniopoulos, A., E. Genitsaris, and I. Balampekou. 2012. "The Metropolitan Transport Authority in Europe. Towards a Methodology for Defining Objectives, Responsibilities and Tasks." Procedia-Social and Behavioral Sciences, 48: 2804-2815.

Nash, C., and Bray, D. 2014. "Workshop 5 Report: The Roles and Responsibilities of Government and Operators." Research in Transportation Economics, 48: 286-289.

Preston, J. 2010. “What's So Funny about Peace, Love and Transport Integration?" Research in Transportation Economics, 29 (1): 329-338.

Masi, C. 2009. "Urban Governance, Public Transport and the Role of the Organising Authorities." Public Transport International, November/December: 4-6.

Schuchmann, A., and S. Papadimitriou. 2009. "The Need for Restructuring of Authorities in Eastern and Central Europe." Public Transport International, November/December: 24-25.

UITP. 2005. "A Market in Motion." International Association of Public Transport. April.

UITP. 2011. "A Vision for Integrated Urban Mobility: Setting up your Transport Authority." International Association of Public Transport. April.

van de Velde, D. 2008. "A New Regulation for the European Public Transport." Research in Transportation Economics, 22 (1): 78-84. 
Zegras, C., J. Nelson, R. Macário, and C. Grillo. 2013. "Fiscal Federalism and Prospects For Metropolitan Transportation Authorities in Portugal." Transport Policy, 29, September: 1-12.

\section{About the Author}

STEVE WRIGHT (s.d.wright@abdn.ac.uk) is a Research Fellow in the Centre for Transport Research at the University of Aberdeen. Following a Ph.D. from Newcastle University and subsequent research work in traffic control and network flow modelling, he has more recently been involved in a variety of projects related to the planning and operational aspects of public and shared transport and in the application of new technologies to facilitate and promote the provision of such services. 